\title{
Defects in Sensory Axon Growth Precede Neuronal Death in Brn3a-Deficient Mice
}

\author{
S. Raisa Eng, ${ }^{1}$ Kevin Gratwick, ${ }^{1}$ Jerry M. Rhee, ${ }^{1}$ Natalia Fedtsova, ${ }^{1}$ Lin Gan, ${ }^{3}$ and Eric E. Turner ${ }^{1,2}$ \\ ${ }^{1}$ Department of Psychiatry and ${ }^{2}$ Program in Neuroscience, University of California, San Diego and San Diego Veterans \\ Affairs Medical Center, La Jolla, California 92093 and ${ }^{3}$ Center for Aging and Developmental Biology, University of \\ Rochester, Rochester, New York 14642
}

Brn3a/Brn-3.0 is a POU-domain transcription factor expressed in primary sensory neurons of the cranial and dorsal root ganglia and in specific neurons in the caudal CNS. Mice lacking Brn3a undergo extensive sensory neural death late in gestation and die at birth. To further examine Brn3a expression and the abnormalities that accompany its absence, we constructed a transgene containing $11 \mathrm{~kb}$ of Brn3a upstream regulatory sequence linked to a LacZ reporter. Here we show that these regulatory sequences direct transgene expression specifically to Brn3a peripheral sensory neurons of the cranial and dorsal root ganglia. Furthermore, expression of the $11 \mathrm{~kb} / \mathrm{LacZ}$ reporter in the sensory neurons of the mesencephalic trigeminal, but not other Brn3a midbrain neurons, demonstrates that cellspecific transgene expression is targeted to a functional class of neurons rather than to an anatomical region. We then interbred the $11 \mathrm{~kb} / \mathrm{LacZ}$ reporter strain with mice carrying a null mutant allele of Brn3a to generate $11 \mathrm{~kb} / \mathrm{LacZ}$, Brn3a knockout mice. $\beta$-Galactosidase expression in these mice reveals significant axonal growth defects, including excessive and premature branching of the major divisions of the trigeminal nerve and a failure to correctly innervate whisker follicles, all of which precede sensory neural death in these mice. These defects in

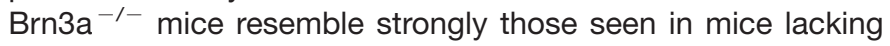
the mediators of sensory pathfinding semaphorin $3 \mathrm{~A}$ and neuropilin-1. Here we show, however, that sensory neurons are able to express neuropilin-1 in the absence of Brn3a.

Key words: POU-domain; homeodomain; Brn3; TrkC; trigeminal ganglion; sensory ganglion; axon guidance
The vertebrate nervous system contains a large number of specific cell types, and how this neuronal diversity is generated is a central question in the study of brain development. Many neurons in the developing brain can be recognized by the expression of specific "neural identity" genes that are first detectable at approximately the time of exit from cell division and may persist throughout embryogenesis. Most such genes discovered to date have been transcription factors, often but not always containing a homeodomain motif (Rubenstein and Puelles, 1994). A specific neural identity gene may be expressed in a recognizable class of neurons, such as the motor neurons of the brainstem and spinal cord, or it may characterize a group of cells that have no other known features in common. Accordingly, they are good candidates for establishing the neuronal phenotypes characterized by, among others, the cellspecific expression of neurotransmitters and their receptors, axonal guidance to selected targets, and synaptic specificity. However, the neuronal properties that are actually regulated by these factors, and how this regulation is accomplished, remain primarily undiscovered.

The "Brn3" or POU-IV class of transcription factors is comprised of three members in vertebrates that share very similar

Received Aug. 8, 2000; revised Oct. 10, 2000; accepted Oct. 25, 2000.

This work was supported in part by Department of Veterans Affairs MERIT funding and VISN 22 Mental Illness Research Education and Clinical Center (E.E.T.), National Institutes of Health Training Grant 5-T32-MH19934 (N.F.), and National Institutes of Health Awards HD33442, MH58447, and MH01581. N.F. and E.E.T. are National Alliance for Research on Schizophrenia and Depression Young Investigators. We thank Dr. Martin Paulus for help with the statistical analysis, and Drs. Alun Davies, Ronald S. Goldstein, and David Anderson for helpful discussions. We also thank Drs. Louis Reichardt and Eric Huang for providing the Trk mutant mouse strains and Dr. David Ginty for the Npn-1 antiserum.

Correspondence should be addressed to Eric E. Turner, Department of Psychiatry, 0603, University of California, San Diego, 9500 Gilman Drive, La Jolla, CA 92093-0603. E-mail: eturner@ucsd.edu.

Copyright (C) 2001 Society for Neuroscience 0270-6474/01/210541-09\$15.00/0
DNA recognition properties to their invertebrate counterparts (Gruber et al., 1997). The three vertebrate Brn3 genes, Brn3a/Brn3.0, Brn3b/Brn-3.2, and Brn3c/Brn-3.1, are expressed primarily in the nervous system, in somewhat overlapping yet distinctive patterns. Null mutants of Brn3b are viable but exhibit defects in retinal ganglion cell development (Erkman et al., 1996; Gan et al., 1996). Brn3 $\mathrm{c}^{-1-}$ mice also survive but show a loss of vestibular and auditory hair cells and the associated sensory ganglia (Erkman et al., 1996; Xiang et al., 1997a).

Brn3a is the most widely expressed member of this class, and mice lacking this factor die at birth. In these mice, the majority of neurons comprising the trigeminal and dorsal root ganglia (DRG) undergo apoptosis in late embryogenesis, and the neurons of some Brn3a-expressing CNS nuclei, such as the red nucleus, also fail to survive (McEvilly et al., 1996; Xiang et al., 1996). In the trigeminal ganglion, neuronal death is preceded by the loss of expression of the Trk family of neurotrophin receptors (Huang et al., 1999). It is not surprising that Brn3a neurons initially develop normally in Brn3a knock-out animals but die at subsequent developmental stages, because Brn3a expression is initiated just before (sensory system) or after (CNS) neurons exit the cell cycle (Fedtsova and Turner, 1995).

Here we show that a transgene containing $11 \mathrm{~kb}$ of Brn3a 5 '-flanking sequence targets reporter expression specifically to the sensory neurons of the PNS and mesencephalic trigeminal nucleus but not to the other CNS sites of Brn3a expression. This 11 $\mathrm{kb} / \mathrm{LacZ}$ reporter was then used to trace the development of sensory neurons and their axons in Brn3a knock-out and heterozygous control mice. These studies reveal a marked defect in sensory axon growth in the absence of Brn3a and thus suggest an explana- 

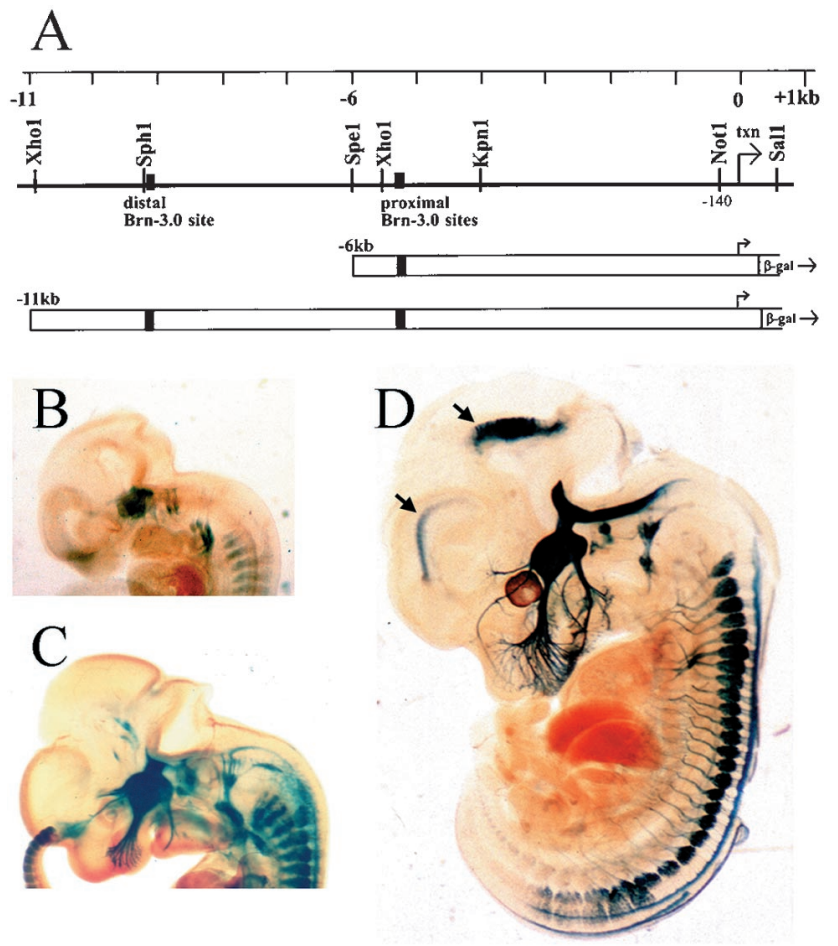

Figure 1. Brn3a $5^{\prime}$-flanking sequences target reporter gene expression to the sensory nervous system. $A$, Structure of the $5^{\prime}$-regulatory region of the mouse brn $3 a$ locus. Transcription is initiated from multiple closely spaced sites $\sim 300 \mathrm{bp}$ upstream from the start of Brn3a translation. The positions of the previously identified distal and proximal autoregulatory sites are indicated (Trieu et al., 1999). Transgene constructs were produced by linking 6 or $11 \mathrm{~kb}$ of $5^{\prime}$-flanking sequence to the LacZ expression cassette at the Brn3a translational start site. $B-D$, The $11 \mathrm{~kb} / \mathrm{Brn} 3 \mathrm{a}$ transgenic construct targets LacZ expression specifically to the sensory system in E11.5, E12.5, and E14 mice, respectively. $B$ and $C$ show one of three transgenic lines that targeted LacZ specifically, and $D$ shows a second independent line. A third line is used for the experiments shown in subsequent figures. Arrows in $D$ indicate areas of ectopic expression in the neuroepithelium of the forebrain and tegmentum that varied between transgenic lines.

tion for the extensive sensory neural death that occurs in these mice.

\section{MATERIALS AND METHODS}

Transgenic mice. Transgene constructs were generated by inserting a series of genomic subclones of the mouse Brn3a locus into the vector pSDKLacZpA (Logan et al., 1993), which contains a Kozak consensus translational start site, the Escherichia coli LacZ gene, and an SV-40 intron/splice/polyadenylation site. Brn3a genomic sequences were derived form a parent P1 clone that has been described previously (Trieu et al., 1999). To generate the transgene constructs, we used PCR to produce a fragment extending from a Not I site located at -140 bp relative to the start of transcription to an inserted HindII site immediately $5^{\prime}$ to the Brn3a initiator methionine codon, thus including the native Brn3a transcriptional start site and 5'-UTR within the PCR product, which was then ligated into pSDKLacZpA. Genomic fragments extending from the NotI site to the SpeI site at $-6 \mathrm{~kb}$, and the $\mathrm{XhoI}$ site at $-11 \mathrm{~kb}$ upstream from the start of translation were then inserted into this promoter construct in native orientation to complete the $6 \mathrm{~kb} / \mathrm{LacZ}$ and $11 \mathrm{~kb} / \mathrm{LacZ}$ transgenes (Fig. $1 A$ ).

Transgene DNA was injected into CB6F2 oocytes, and the founder animals were genotyped by PCR for integration of the LacZ transgene, as described below. Founders were bred with $\mathrm{C} 57 \mathrm{BL} / 6 \mathrm{~J}$ mice, and transgenic lines were carried in a C57BL/6J genetic background. Mice analyzed for transgene expression were at least two generations removed from the founder animals, and analysis of F1 $11 \mathrm{~kb} / \mathrm{LacZ}$ mice by Southern blotting indicated integration of the transgenes at a single locus. The mice carrying null alleles for Brn3a (Xiang et al., 1996) and TrkC (Klein et al., 1994) have been described previously.

Mice were genotyped by PCR using tail DNA samples from 4-week-old mice or from embryonic hind limb, tail, or amnion tissue. The LacZ reporter transgene was assayed using PCR primers within the LacZ cassette (CACAGATGTGGATTGGCGAT and CATAATTCAATTCGCGCGTCCC). Brn3a wild-type and null alleles were assayed using primers within the Brn3a coding sequence (GGCGTCCATCTGCGACTCGGACAG and CAGGATAACGGACAGTCTAAATGA) and in the inserted neomycin resistance cassette (GGAGAGGCTATTCGGCTATGACTG and CTCTTCGTCCAGATCATCCTGATC). The TrkC wild-type and null alleles were assayed using one primer common to both the wild-type and targeted alleles (GTCCCATCTTGCTTACCCTGAGG) and a second wild-type-specific primer (CTGAAGTCACTGGCTAGAGTCTGGG) or a knock-out-specific primer (CCAGCCTCTGAGCCCAGAAAGC).

Staged embryos were generated for analysis by interbreeding mice of the appropriate genetic background, with the assignment of noon on the day after the appearance of a mucous plug in mated animals as embryonic day 0.5 (E0.5). Embryos were further staged by size and developmental landmarks as described by Theiler (1989).

$\beta$-Galactosidase staining and immunohistochemistry. For whole-mount staining for $\beta$-galactosidase ( $\beta$ gal) activity, embryos were fixed in $3.7 \%$ formaldehyde in PBS for $30 \mathrm{~min}$ (up to $2 \mathrm{hr}$ for E16.5 embryos) and then rinsed in $100 \mathrm{~mm}$ potassium phosphate, $\mathrm{pH} 7.4$, containing $5 \mathrm{~mm}$ EGTA, $2 \mathrm{mM} \mathrm{MgCl}, 0.02 \%$ Nonidet P-40, and $0.01 \%$ sodium deoxycholate. Staining was performed in the rinse solution to which was added 0.5 $\mathrm{mg} / \mathrm{ml} \mathrm{X}$-gal, $5 \mathrm{~mm}$ potassium ferricyanide, and $5 \mathrm{~mm}$ potassium ferrocyanide. Embryos were stained several hours to overnight at $37^{\circ} \mathrm{C}$, rinsed in the same buffer, dehydrated in graded ethanols, and then cleared in 1:2 benzyl alcohol/benzyl benzoate. Intact newborn brains were also fixed and stained using this procedure, sectioned in a vibratome at intervals of $100 \mu \mathrm{M}$, and then cleared in 50\% glycerol-PBS.

For immunohistochemistry of Brn3a in tissue sections, harvested embryos were fixed in $4 \%$ formaldehyde in $60 \%$ ethanol for $30 \mathrm{~min}$ to $2 \mathrm{hr}$ depending on the embryonic stage, washed with $70 \%$ ethanol, dehydrated, embedded in histoplast, and sectioned at $5 \mu \mathrm{m}$ as in previous work (Fedtsova and Turner, 1995). The rabbit anti-Brn3a/Brn3.0 antiserum used has been described previously (Fedtsova and Turner, 1995). Immunohistochemistry for $\beta$-gal and neuropilin-1 (Npn1) was performed in frozen sections. Embryos were fixed in $4 \%$ paraformaldehyde in PBS, rinsed in PBS, frozen at $-20^{\circ} \mathrm{C}$ in OCT solution, and cryostat sectioned at intervals of $20 \mu \mathrm{m}$. Rabbit anti- $\beta$-gal was obtained from 5 Prime $\rightarrow 3$ Prime, Inc. (Boulder, CO), and rabbit anti-Npn1 antiserum was a gift of Dr. David Ginty (The Johns Hopkins University School of Medicine, Baltimore, MD) (Kolodkin et al., 1997). Secondary anti-rabbit antiserum conjugated with Alexa Fluor 488 was obtained from Molecular Probes (Eugene, OR).

\section{RESULTS}

\section{The Brn3a locus contains regulatory sequences specific for sensory neurons}

Brn3a is expressed in a complex but highly specific pattern in the sensory peripheral nervous system and in CNS nuclei, including the medial and lateral habenula, specific tectal lamina, red nucleus, interpeduncular nucleus, mesencephalic trigeminal nucleus (mes5), and inferior olive (Gerrero et al., 1993; Fedtsova and Turner, 1995; Turner et al., 1996; Xiang et al., 1997b; Trieu et al., 1999). To identify the regulatory sequences determining all or part of this expression pattern, we produced a series of transgene constructs linking fragments of the Brn3a locus to a LacZ reporter (Logan et al., 1993) and examined the resulting patterns of $\beta$-galactosidase expression.

Brn3a transcription is initiated from a cluster of sites that do not contain a "TATA" sequence and reside $\sim 300$ bp upstream from the Brn3a initiator methionine (Trieu et al., 1999). The first transgene construct tested contained $\sim 6 \mathrm{~kb}$ of Brn3a 5'-flanking sequence, the native transcriptional start site, and $\sim 300$ bp corresponding to the $5^{\prime}$-untranslated part of the Brn3a mRNA (Fig. $1 A)$. This transgene yielded specific but very weak expression in 

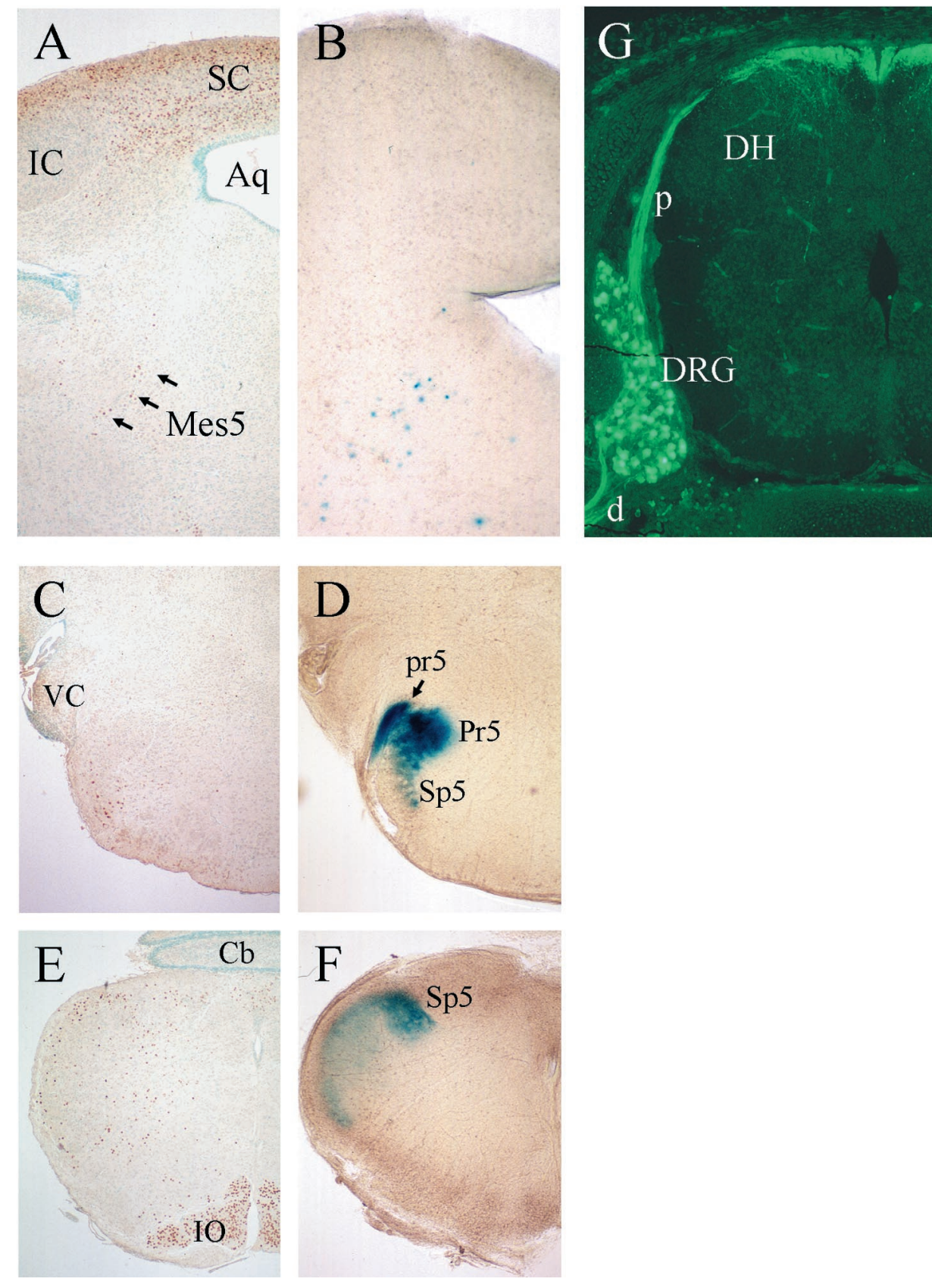

Figure 2. Brn3a regulatory sequences target gene expression only to primary sensory neurons, regardless of anatomical location. A cross-section of the midbrain of a newborn (P0) mouse stained for Brn3a by immunohistochemistry $(A)$ and a vibratome section at a similar level stained for $\beta$-gal activity $(B)$ show that $\beta$-gal expression controlled by Brn3a regulatory sequences is confined to primary sensory neurons of the mes5 (arrows) in the midbrain and not the numerous Brn3aexpressing tectal neurons. Comparison of Brn3a immunohistochemistry $(C, E)$ and $\beta$-gal activity $(D, F)$ in the $\mathrm{P} 0$ hindbrain shows that the nuclear expression of Brn3a protein in hindbrain reticular neurons and the inferior olivary nucleus is distinct from $\beta$-gal staining that corresponds to the projections of sensory axons to the trigeminal nucleus. In $G$, immunohistochemistry for $\beta$-gal protein shows expression of the LacZ transgene in a cervical dorsal root ganglion of a $\mathrm{P} 0$ mouse and in the associated proximal and distal roots. $A q$, Aqueduct; $C b$, cerebellum; $d$, distal root (of ganglion); $D H$, dorsal horn (of spinal cord); $D R G$, dorsal root ganglion; $I C$, principal nucleus of inferior colliculus; $I O$, inferior olive; mes5, mesencephalic trigeminal; $p$, proximal root (of ganglion); Pr5, principal trigeminal nucleus; $p r 5$, principal tract of the trigeminal; Sp5, spinal trigeminal nucleus; $S C$, superior colliculus; $V C$, ventral cochlear nucleus. the trigeminal and DRG of E13.5 mice (data not shown). Extension of the targeting construct to include $\sim 11 \mathrm{~kb}$ of $5^{\prime}$-flanking sequence (11 kb/LacZ reporter) strongly enhanced transgene expression (Fig. $1 B-D$ ). Three of the four $11 \mathrm{~kb} / \mathrm{LacZ}$ lines that were examined showed specific expression in the trigeminal (fifth) ganglion, vestibulocochlear (eighth) ganglion, superior (ninth) ganglion, and DRG, whereas one of the four lines showed weak $\beta$-gal expression not associated with the expression pattern of Brn3a. None of the $11 \mathrm{~kb} / \mathrm{LacZ}$ transgenic lines showed $\beta$-gal expression in the Brn3a-expressing neurons in the habenula, superior colliculus, or midbrain tegmentum. However, expression in small regions of the forebrain and tegmental neuroepithelium was observed in one line (Fig. $1 D$ ) in a pattern not associated with Brn3a and was presumably attributable to insertion sitedependent regulatory elements.

The scattered neurons of the mes5, concentrated near the aqueduct in the caudal midbrain, provide sensory innervation of the masticatory muscles and teeth and constitute the only sensory neurons (exclusive of special senses) located within the CNS (Rokx et al., 1986). Thus, these neurons provide a test of whether the Brn3a regulatory sequences contained in the $11 \mathrm{~kb} / \mathrm{LacZ}$ reporter direct expression to the sensory ganglia based on anatomical location in the PNS or to a functionally similar class of neurons independent of location. Examination of the midbrain by immunohistochemistry for Brn3a protein in the newborn [postnatal day $0(\mathrm{P} 0)$ ] mouse (Fig. $2 A$ ) revealed extensive nuclear staining within the tectal lamina and also in the scattered mes5 neurons. In contrast, $\beta$-gal activity in $11 \mathrm{~kb} / \mathrm{LacZ}$ mice appeared only in the mes5 (Fig. 2B).

We then compared Brn3a immunohistochemistry with $\beta$-gal staining in hindbrain sections of $11 \mathrm{~kb} / \mathrm{LacZ}$ mice to determine whether the LacZ expression observed in whole mounts origi- 
Figure 3. Sensory axon growth in Brn3a null mice. Brn3a ${ }^{+-}$control $(A, C, E, G)$ and $\mathrm{Brn3a}^{-/-}(B, D, F, H)$ E13.5 embryos were stained for $\beta$-gal activity and $(A-F)$ were hemisected before clearing. The major axonal projections of the sensory ganglia are present in Brn3a knock-out mice $(A, B)$, but there is extensive abnormal branching, particularly in the ophthalmic and maxillary divisions of the trigeminal $(C, D$, arrows $)$. Occipital sensory structures, which normally regress by this stage $(E)$, persist abnormally in Brn3a null mice $(F$, arrows $)$. Dorsal views of control and Brn3a knock-out embryos show that the aberrant sensory axons do not cross the midline in either the CNS or the periphery $(G, H)$. The patterns of axonal growth in $11 \mathrm{~kb} / \mathrm{LacZ},{\mathrm{Brn} 3 \mathrm{a}^{-/}}^{--}$and heterozygous controls were very similar in specimens obtained from three different litters staged from E13.5 to E14.5. In preliminary experiments, it was observed that

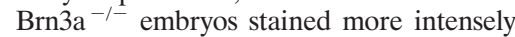
than $\mathrm{Brn} 3 \mathrm{a}^{+/-}$littermates, consistent with negative autoregulation by Brn3a. Because we wished to ensure that no axonal projections would be overlooked in control embryos as a result of lower reporter expression, controls were deliberately stained two to four times longer than knock-out embryos. This overstaining resulted in very intense signal in the sensory ganglia of controls $(A, C)$ and some diffusion of the $\beta$-gal reaction product into the surrounding tissue of the ganglia. $5 g$, Trigeminal ganglion; $8 g$, vestibulocochlear ganglion; $9 g$, superior ganglion of glossopharyngeal nerve; $C 2$, dorsal root ganglion corresponding to cervical segment $\mathrm{C} 2 ; \mathrm{Mn}$, mandibular division of trigeminal nerve; $M x$, maxillary division of trigeminal nerve; $O p$, ophthalmic division of trigeminal nerve; Pr5, principal trigeminal nucleus.
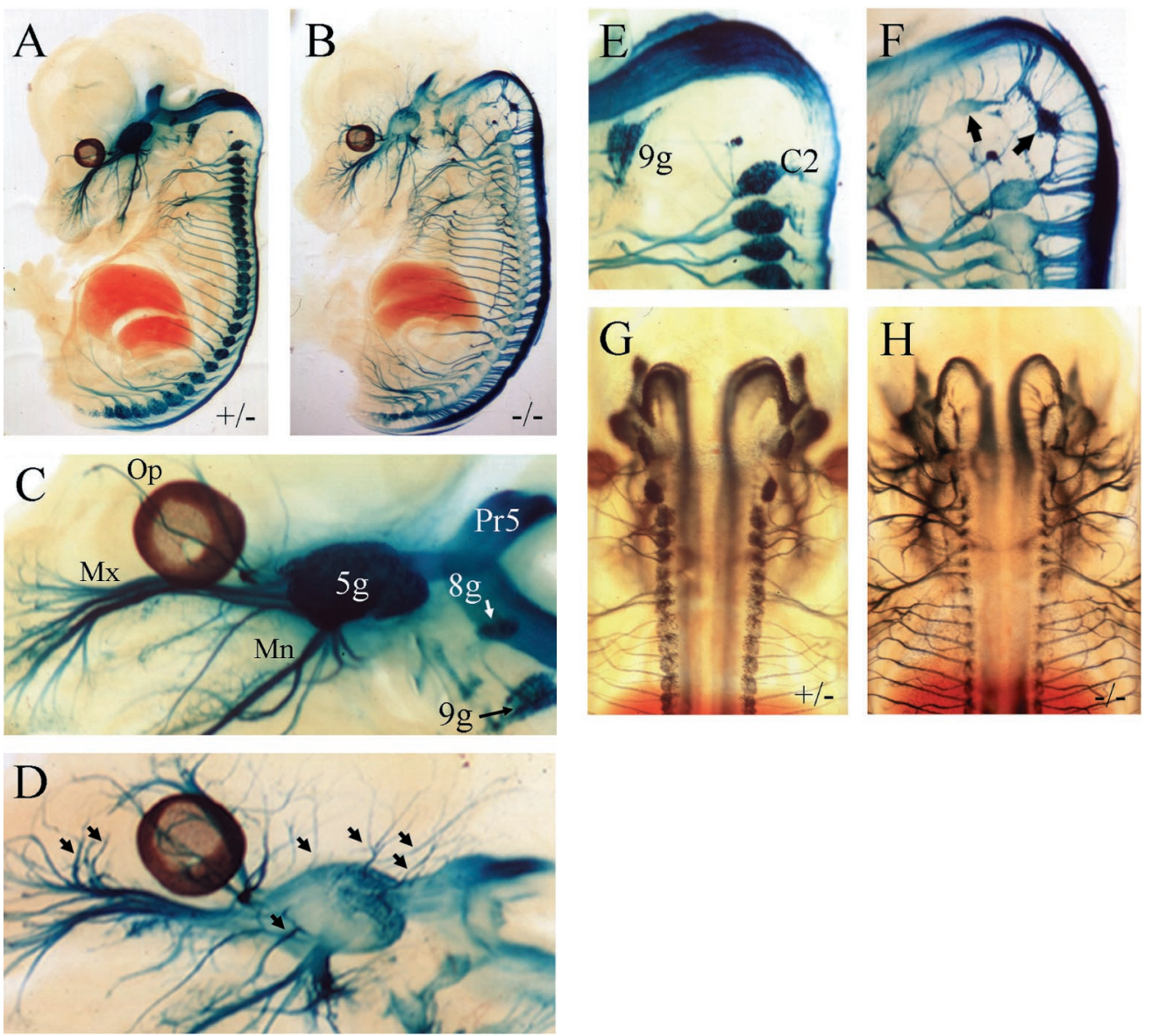

nated in CNS neurons or in sensory axons. In the hindbrain, scattered reticular neurons, the nucleus ambiguus, and the inferior olivary nucleus stained for Brn3a protein (Fig. $2 C, E$ ). $\beta$-Gal activity showed a diffuse pattern characteristic of expression in axonal tracts rather than cell bodies (Fig. 2D,F). Staining was confined to the principal nucleus of the trigeminal (Pr5) and the spinal trigeminal nucleus (Sp5), which did not contain Brn3a immunoreactivity, except for a few adjacent reticular neurons. Similarly, in the spinal cord, immunofluorescent staining for $\beta$-gal in $11 \mathrm{~kb} / \mathrm{LacZ}$ mice was strong in the DRG, its central and peripheral roots, and in white matter adjacent to the dorsal horn (Fig. 2G). However, no staining was noted in the intermediate spinal gray, in which the Brn3a-expressing spinal neurons reside (Fedtsova and Turner, 1997). Together, these results show that $\beta$-gal expression in the hindbrain and spinal cord originates entirely in peripheral sensory neurons, that the $11 \mathrm{~kb} / \mathrm{LacZ}$ transgene is specific for these neurons, and that reporter expression is determined by functional neuronal class rather than by anatomical location. Experiments are underway to determine whether these Brn3a regulatory sequences function as a discrete sensory enhancer and whether a similar independent regulatory region controls expression of Brn3a in the CNS.

\section{Sensory axon growth is defective in Brn3a null mice}

Brn3a knock-out mice have been shown to exhibit profound defects in the development of the sensory ganglia. The trigeminal ganglia of these mice fail to express TrkC and show a significant secondary loss of TrkA- and TrkB-expressing neurons by E15.5, followed by extensive sensory apoptosis (Huang et al., 1999). To better understand sensory neurogenesis in mice lacking Brn3a, we interbred $11 \mathrm{~kb} / \mathrm{LacZ}$ reporter mice with an existing mouse strain containing a Brn3a null allele (Xiang et al., 1996). Unexpectedly, the $11 \mathrm{~kb} / \mathrm{LacZ}, \mathrm{Brn} 3 \mathrm{a}^{-/-}$mice exhibit a profound defect in sensory axonal growth that precedes the period of Trk receptor loss and sensory neural death.

Examination of $11 \mathrm{~kb} / \mathrm{LacZ}, \mathrm{Brn} 3 \mathrm{a}^{-/-}$embryos beginning at E11.5, when $\beta$-gal expression can first be detected, showed that the cranial sensory and dorsal root ganglia condensed as expected. Initially, the ophthalmic, maxillary, and mandibular branches of the trigeminal nerve also formed normally and began to grow toward their peripheral targets. However, by E13.5,

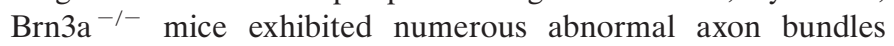
emerging directly from the trigeminal ganglion (Fig. $3 B, D$ ). In addition, premature branching of the nerve is observed, particularly of the ophthalmic and maxillary divisions. Examination of the dorsal aspect of $11 \mathrm{~kb} / \mathrm{LacZ}, \mathrm{Brn} 3 \mathrm{a}^{-/-}$and control embryos showed that the aberrant sensory axons did not cross the midline of the embryo and also that the projections of the sensory ganglia to the hindbrain and spinal cord continued to obey a midline boundary (Fig. 3G,H).

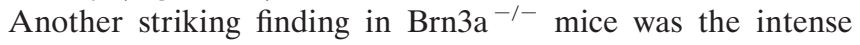



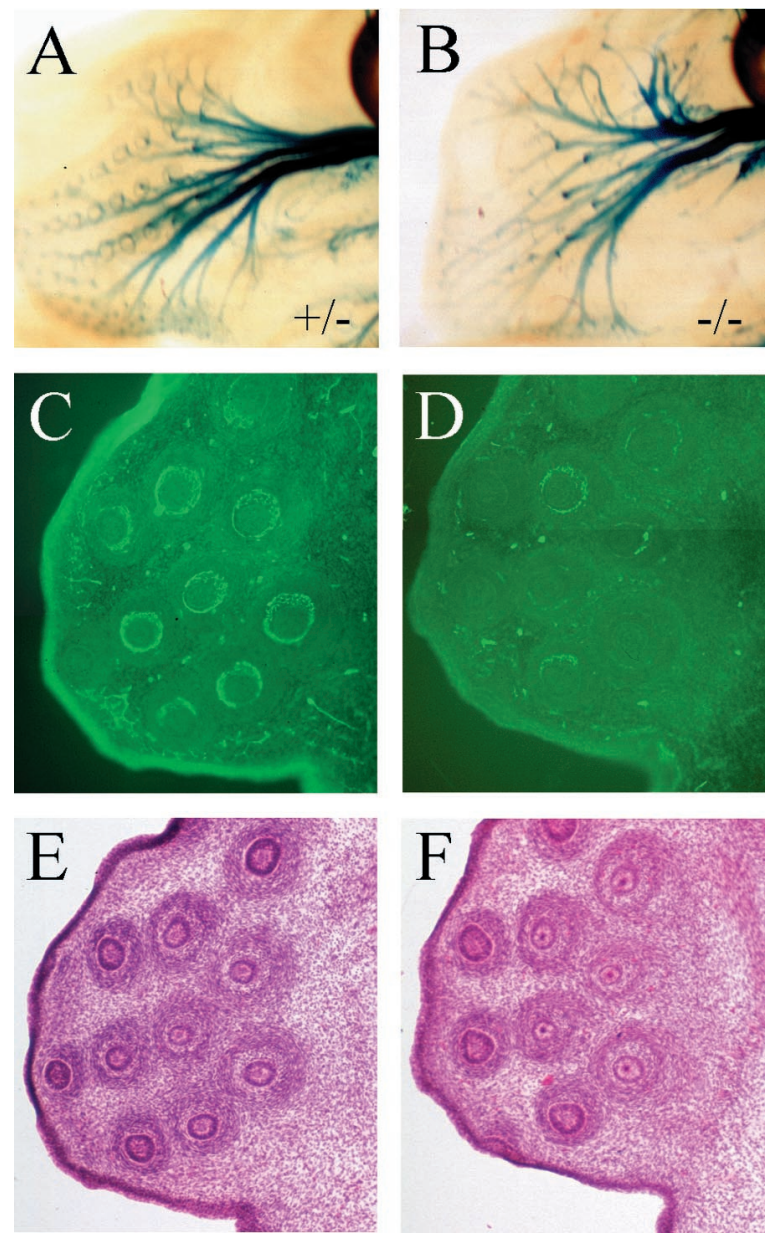

Figure 4. Sensory axons fail to innervate whisker follicles in Brn3a null \left. mice. The whisker follicles of ${\mathrm{Brn} 3 \mathrm{a}^{+/-}}^{+/} A, C, E\right)$ and ${\mathrm{Brn} 3 \mathrm{a}^{-/-}}^{-}(B, D, F)$ embryos were examined in detail at E13.5 for the expression of $\beta$-gal by activity staining $(A, B)$ and immunohistochemistry for $\beta$-gal protein $(C$, $D)$. At this stage, most of the follicles of ${\mathrm{Brn} 3 \mathrm{a}^{+/-}}$mice $\left(\right.$and $\mathrm{Brn} 3 \mathrm{a}^{+/+}$ mice; data not shown) were completely encircled by $\beta$-gal-containing

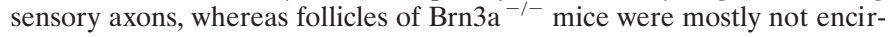
cled. The follicles of both embryos appeared normal by hemoxylin-eosin histology $(E, F)$.

expression of the $\beta$-gal transgene in peripheral structures associated with the most rostral sclerotomes in the early embryo (Fig. $3 F$, arrows). In all avian and mammalian species examined, neural crest precursors condense into ganglia in this region and then regress (Lim et al., 1987; Geffen and Goldstein, 1996; Rosen et al., 1996; Kant and Goldstein, 1999). In the mouse, the most anterior permanent dorsal root ganglion is associated with the spinal segment $\mathrm{C} 2$. The embryonic ganglia associated with $\mathrm{C} 1$ ("Froriep's ganglion") and the occipital segments O1-O4 degenerate before E12 (Kessel and Gruss, 1991).

In $\mathrm{Brn3a}^{+/-}$mice, expression of the $11 \mathrm{~kb} / \mathrm{LacZ}$ transgene adjacent to the occipital segments was discernable at E12.5 (Fig. $1 C$ ) but was undetectable at later stages (Fig. $3 E$ ). In Brn3a knock-out mice examined at E13.5, intensely staining neuronal structures were distributed between the ninth ganglion and the first permanent DRG at C2 (Fig. 3F) and were connected to the hindbrain at their corresponding axial levels. Ultimately, these structures were observed to disappear with the death of the rest of the Brn3a sensory neurons after E15.5.

Considering the extensive axonal defects in $\mathrm{Brn}_{3} \mathrm{a}^{-1-}$ mice, we
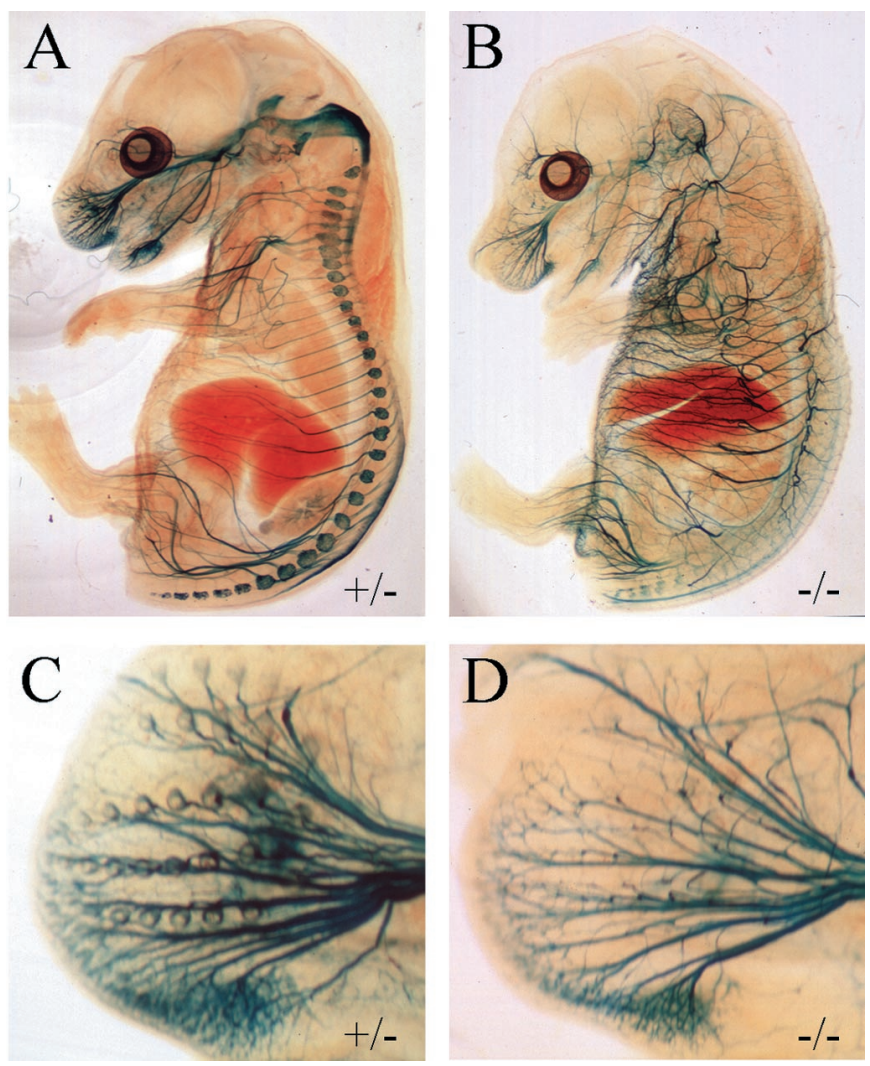

Figure 5. Sensory neuronal death in late gestation in Brn3a null mice. Brn3a $^{+-}(A, C)$ and Brn3a ${ }^{-1-}(B, D)$ embryos were examined by $\beta$-gal activity staining at E16.5, after the onset of sensory neural apoptosis. Although the sensory ganglia can no longer be seen in the Brn3a-1embryo, $\beta$-gal activity persists in the sensory axons, and numerous defects in axonal guidance can be seen in the mutant embryos $(B)$. The defect in the encirclement of the whisker follicles noted at E13.5 also persists at this stage $(D)$.

wished to know whether the trigeminal neurons in these mice could effectively innervate their peripheral targets. One of the major targets of the maxillary division of the trigeminal are the whisker follicles, or vibrissae. The vibrissal follicles are complex sensory organs containing several kinds of sensory nerve endings, including pain fibers and multiple types of mechanoreceptors (Fundin et al., 1997). When stained for $\beta$-gal activity in E13.5

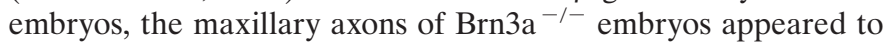
end abruptly before reaching their targets (Fig. 4A,B). Whisker follicles were then examined in serial sections using $\beta$-gal immunofluorescence (Fig. 4C,D). We examined sections through the central portion of 29 follicles from two Brn3a ${ }^{+/-}$embryos and 34 follicles from two Brn-3a-1- littermates. Encirclement of the follicle by sensory axons was scored in the section showing the most complete circle as complete $(>90 \%)$, partial $(50-90 \%)$, or incomplete $(<50 \%)$. Among Brn3a ${ }^{+/-}$follicles, 19 showed complete, 7 partial, and 3 incomplete encirclement. Among Brn3a ${ }^{-1-}$ follicles, 7 showed complete, 6 partial, and 21 incomplete encirclement $\left(\chi^{2}\right.$ test; $p<0.01$ for the difference between Brn3a ${ }^{+-}$ follicles and all follicles examined; $p<0.02$ for the difference between $\mathrm{Brn} 3 \mathrm{a}^{-/-}$and the entire sample).

We then examined $11 \mathrm{~kb} / \mathrm{LacZ}, \mathrm{Brn} 3 \mathrm{a}^{-1-}$ mice to determine the fate of the sensory neurons and their axons later in development. Beginning at approximately E15.5, sensory neurons have been shown previously to undergo extensive apoptosis in 

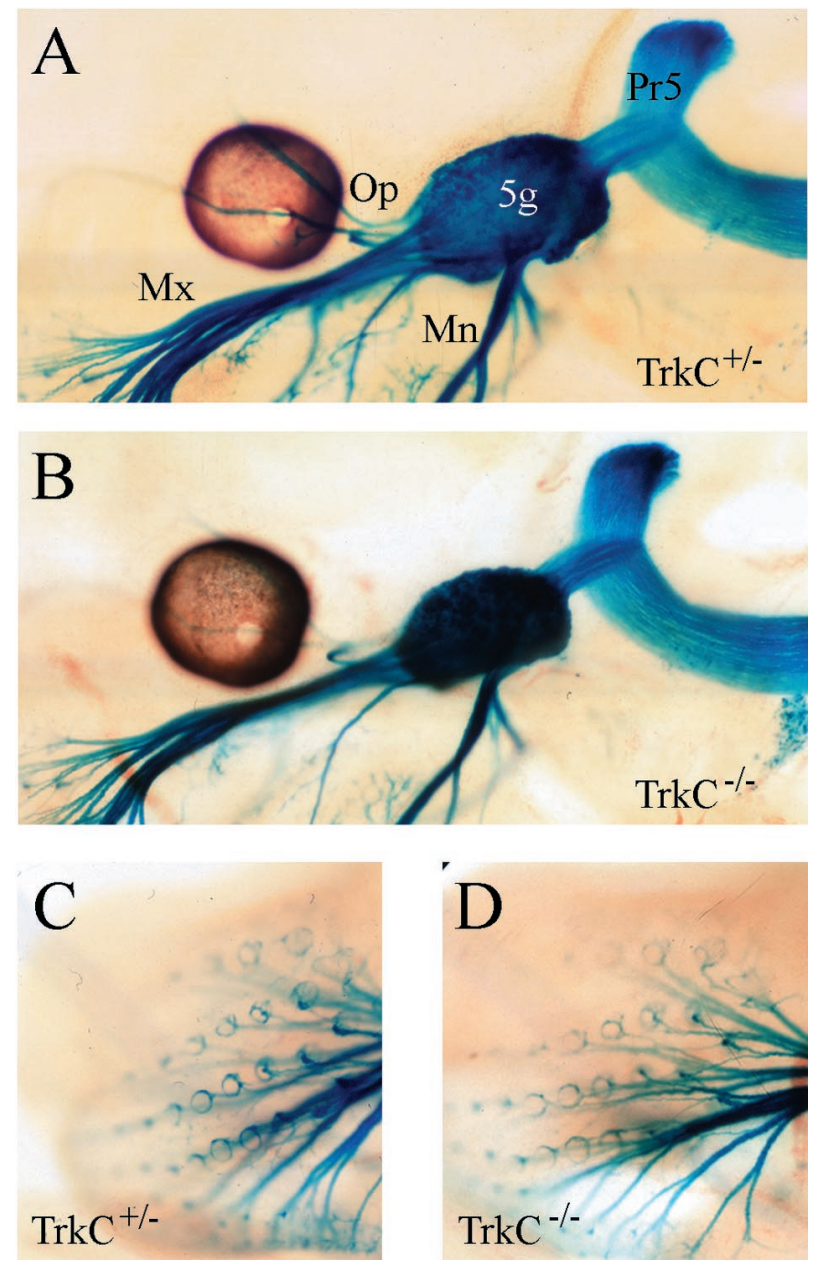

Figure 6. Sensory axon guidance in TrkC neurotrophin receptordeficient mouse embryos. Mice carrying the $11 \mathrm{~kb} / \mathrm{LacZ}$ transgene were interbred with $\mathrm{TrkC}^{+/-}$mice, and then the resulting $11 \mathrm{~kb} / \mathrm{LacZ}$, TrkC ${ }^{+/-}$mice were crossed with TrkC $^{+/-}$mice to produce litters containing the $11 \mathrm{~kb} / \mathrm{LacZ}$, TrkC ${ }^{+/-}$embryos $(A, C)$ and $11 \mathrm{~kb} / \mathrm{LacZ}$, $\operatorname{TrkC}^{-1-}(B, D)$ littermates. Examined at E13.5, TrkC mutant embryos lack the ectopic trigeminal branches noted in Brn3a null mice $(A, B)$ and show normal encirclement of the whisker follicles by $\beta$-gal-expressing sensory axons $(C, D) .5 g$, Trigeminal ganglion; $M n$, mandibular division, trigeminal nerve; $M x$, maxillary division, trigeminal nerve; $O p$, ophthalmic division, trigeminal nerve; $\operatorname{Pr} 5$, principal trigeminal nucleus.

Brn3a $^{-/-}$mice (McEvilly et al., 1996; Xiang et al., 1996; Huang et al., 1999). However, $\sim 30 \%$ of trigeminal neurons survive until birth (Huang et al., 1999). From pervious studies, it has not been clear whether the surviving cells are a subset of neurons that normally express Brn3a but do not require its activity for survival, or neurons that do not express this factor, because no independent markers have been available to identify the Brn3a-expressing neurons in Brn3a null mice. At E16.5 in $11 \mathrm{~kb} / \mathrm{LacZ}, \mathrm{Brn3a}{ }^{-/-}$ mice, sensory cell bodies in the trigeminal, eighth and ninth cranial ganglia, and DRG could no longer be visualized by $\beta$-gal staining except in the developmentally youngest sacral ganglia (Fig. 5A,B). This confirms that the loss of Brn3a-expressing neurons is complete or nearly so at this stage and that all sensory neurons that express Brn3a absolutely require it for survival. Because the surviving neurons in the sensory ganglia do not express the $11 \mathrm{~kb} / \mathrm{LacZ}$ transgene, they probably represent a subclass of cells that are normally Brn3a-negative at this developmental stage.
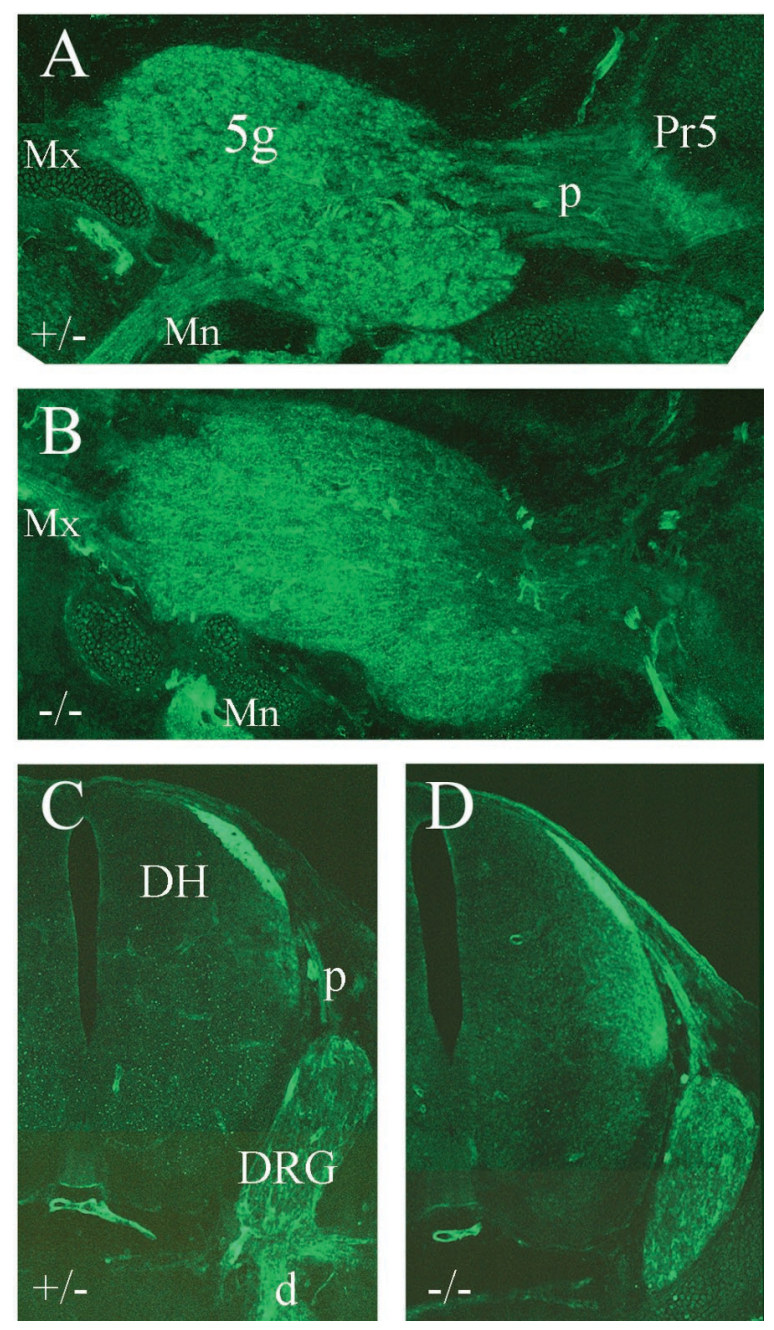

Figure 7. Neuropilin-1 expression in control and Brn3a-deficient mice. Brn3a $^{+-}(A, C)$ and Brn3a ${ }^{-1-}(B, D)$ embryos were examined at E14 for Npn1 immunoreactivity. Sagittal sections through the trigeminal ganglion and hindbrain $(A, B)$ and cross-sections through the cervical spinal cord and dorsal root ganglion $(C, D)$ show Npn1 expression in the expected sensory structures in both the presence and absence of Brn3a. 5g, Trigeminal ganglion; $d$, distal root (of ganglion); $D H$, dorsal horn (of spinal cord); $D R G$, dorsal root ganglion; $M n$, mandibular division, trigeminal nerve; $M x$, maxillary division, trigeminal nerve; $p$, proximal root (of ganglion).

The $11 \mathrm{~kb} / \mathrm{LacZ}, \mathrm{Brn} 3 \mathrm{a}^{-/-}$mice examined at E16.5 also exhibited a loss of $\beta$-gal activity in the proximal part of the major divisions of the trigeminal nerve and in the CNS trigeminal projections (Fig. $5 B$ ), consistent with axonal degeneration after the death of these neurons. However, $\beta$-gal activity was still detectable in the distal parts of the sensory nerves, and these appeared markedly overgrown compared with control littermates, with abnormal dorsal and recurrent branches that violated segmental boundaries (Fig. $5 A, B$ ). Closer examination of the whisker pad at E16.5 (Fig. 5C,D) shows that the defect in encirclement of whisker follicles noted at E13.5 persists and is not just a delay in the innervation of these structures.

\section{Loss of neurotrophin or semaphorin receptors does not account for defective axonal guidance in $\mathrm{Brn3a}^{-/-}$ mice}

Loss of TrkA and TrkB expression from the majority of trigeminal neurons in Brn3a ${ }^{-/-}$mice occurs after E13.5 (Huang et al., 
1999), suggesting that the loss of these receptors cannot account for the abnormal axonal growth observed here. However, TrkC expression is not detectable at any time in embryogenesis in

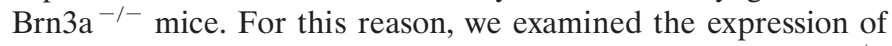
$\beta$-gal under regulation of the $11 \mathrm{~kb} / \mathrm{LacZ}_{\text {reporter in }} \mathrm{TrkC}^{-1-}$ mice to see whether the loss of TrkC expression is sufficient to alter axonal growth in Brn3a $\mathrm{a}^{-1-}$-expressing neurons. In TrkC knock-out embryos examined at E14, the principal divisions of the trigeminal nerve did not exhibit the abnormal branching observed in the absence of Brn3a (Fig. 6A,B), and the encirclement of the whisker follicles appeared to be complete (Fig. 6C,D).

Trigeminal axon guidance appears to be regulated in part by the ligand semaphorin $3 \mathrm{~A}$ (Sema3A) and by its receptor Npn-1, which together repel sensory axons by inducing growth cone collapse (Kolodkin et al., 1997). Npn-1 is expressed in the trigeminal ganglion, and Npn-1 ${ }^{-/-}$mice exhibit abnormal branching of the major divisions of the trigeminal nerve strongly resembling that observed here in Brn3a $\mathrm{a}^{-1-}$ embryos (Kitsukawa et al., 1997). We therefore wished to know whether Npn-1 expression was altered in the absence of Brn3a. However, for both the trigeminal ganglion (Fig. 7 $A, B$ ) and the DRG (Fig. 7C,D), Npn-1 expression was observed within the ganglia, in the peripheral sensory nerves, and in the CNS areas innervated by the ganglia, in both control and Brn3a knock-out mice. Thus, regulation of Npn-1 expression by Brn3a does not appear to account for the similarity of the phenotypes observed in the null mutants of these two genes.

\section{DISCUSSION}

The POU-domain factor Brn3a is a neural identity gene expressed in specific neurons in the caudal CNS and in cranial and spinal sensory neurons. Previous studies have shown that this factor is required for the survival of sensory neurons and some of the CNS neurons in which it is expressed (McEvilly et al., 1996; Xiang et al., 1996; Huang et al., 1999). Here we have demonstrated that Brn3a is also necessary for the normal growth of sensory axons.

Before this study, little was known about the transcriptional regulation of neural identity and axonal guidance in the sensory system. The basic helix-loop-helix factors neurogenin-1 (Ngn-1) and Ngn-2 have early roles in the development of the sensory ganglia (Perez et al., 1999). However, mutations of these genes lead to the early loss of sensory precursors rather than the late

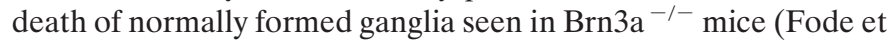
al., 1998; Ma et al., 1998). Mice with mutations at the Pax-3 locus have diminished dorsal root ganglia attributable to defects in neural crest migration but also show some defects in axonal projections of the trigeminal ganglion (Tremblay et al., 1995). Interestingly, Brn3a and the motor neuron marker Islet-1 are both expressed in the differentiating trigeminal ganglion, DRG, and mes5, but have mutually exclusive expression patterns in the rest of the nervous system (Ericson et al., 1992; Fedtsova and Turner, 1997; Cui and Goldstein, 2000; N. Fedtsova, unpublished results). The embryonic death of mice lacking Islet-1 (Pfaff et al., 1996) has thus far prevented a detailed study of the role of Islet- 1 in the sensory system. Finally, recent work on the ETS gene Er81 has shown that this factor, expressed in both proprioceptive sensory neurons and their motor neuron targets, is necessary for the formation of correct connections between these neuronal classes (Arber et al., 2000).

The death of the trigeminal and DRG neurons in Brn3a ${ }^{-1-}$ mice has been attributed to the loss of several components of the neurotrophin signaling system, including the low-affinity NGF receptor (LNGFR), BDNF, TrkA, TrkB, and TrkC (McEvilly et al., 1996; Huang et al., 1999). Target-derived neurotrophins have been shown to be essential for the survival of sensory neurons, initially by surgical manipulation of their target fields (Carr and Simpson, 1978) and the application of anti-NGF antisera (Johnson et al., 1980). More recently, genetic methods have shown each of the neurotrophins and their receptors to be necessary for the survival of a subset of sensory neurons (Snider, 1994), and the loss of all three Trk receptors would be likely to result in the extensive sensory apoptosis observed in Brn3a ${ }^{-1-}$ embryos. However, two major problems arise with the hypothesis that neurotrophins or their receptors are the essential targets of Brn3a regulation in the sensory system. First, although Brn3a is coexpressed with these receptors in sensory neurons, the expression of Brn3a does not coincide well with the expression of any of the Trk receptors, BDNF, or the LNGFR in the autonomic system or CNS. Second,

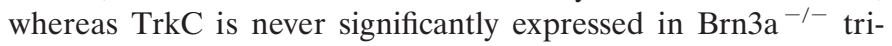
geminal neurons, TrkA and TrkB are coexpressed with Brn3a for several developmental days (E10.5-E15.5) before Trk expression is lost and apoptosis ensues. These findings suggest that the effect of Brn3a on the expression of the neurotrophin receptors may be indirect.

Sensory neuronal death at approximately E15.5 in Brn3a knock-out mice coincides with a period of naturally occurring apoptosis in the developing trigeminal ganglion (E13-E18), which has been reported as encompassing from a negligible number to nearly half of the neuronal population of the ganglion (Davies and Lumsden, 1984; Pinon et al., 1996; Huang et al., 1999) and also corresponds to the time during which death is most increased by the deprivation of target-derived NGF (Pinon et al., 1996). Furthermore, trigeminal neurons lacking Brn3a, taken from before the onset of apoptosis, are supported by NGF in culture (Huang et al., 1999). Thus, our data raise an alternate hypothesis for the mechanism of sensory neural death in Brn3a knock-out mice. It is possible that neuronal death in $\mathrm{Brn} 3 \mathrm{a}^{-1-}$ mice may result from the failure of sensory axons to correctly innervate their targets and access target-derived factors rather than the direct regulation of multiple components of the neurotrophin signaling system by Brn3a.

Here we have demonstrated two significant defects in sensory axon guidance in mouse embryos deficient in Brn3a. First, the major divisions of the trigeminal ganglion develop normally, but trigeminal axons fail to correctly innervate their peripheral targets, particularly the whisker follicles. Second, there are numerous abnormal branches of the trigeminal, particularly of the ophthalmic and maxillary divisions. It remains to be seen what regulatory targets of Brn3a mediate these aspects of sensory guidance and whether the same downstream genes account for both effects.

The most economical explanation for the failure of sensory neurons to innervate peripheral targets in $\mathrm{Brn} 3^{-/-}$mice would be an effect mediated directly by neurotrophins. Neurotrophins have been implicated in growth cone guidance by local chemoattraction using in vitro assays (McFarlane and Holt, 1997; Paves and Saarma, 1997), but in vivo axonal guidance effects have been obscured by the requirement of neurotrophins for sensory neural survival. Recently sensory axon development has been examined in $\operatorname{Trk} \mathrm{A}^{-1-}$ mice in which the sensory ganglia were rescued by the elimination of the mediator of apoptosis BAX (Patel et al., 2000). Like Brn3a-deficient mice, the sensory ganglia of these mice show intact projections to the CNS but defective innervation of the 
periphery, including the whisker follicles. However, it is difficult to explain the failure of trigeminal axons in Brn3a knock-out mice by a TrkA-mediated mechanism, because TrkA and TrkB con-

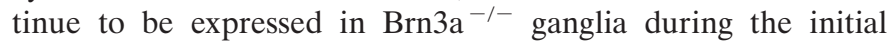
sensory innervation of the skin, at least in the majority of neurons that usually express these factors (Huang et al., 1999). TrkC is absent in Brn3a ${ }^{-1-}$ mice throughout sensory neurogenesis, but as shown here, the Brn3a-expressing sensory neurons in $\mathrm{TrkC}^{-1-}$ mice do not exhibit similar defects in cutaneous innervation. Furthermore, mice lacking neurotrophin-3 and BDNF show normal early development of trigeminal projections (O'Connor and Tessier-Lavigne, 1999). Thus, loss of Trk expression may not be an adequate explanation for the failure of the trigeminal ganglion to innervate the whisker follicles in mice lacking Brn3a.

The sensory axons of Brn3a ${ }^{-1-}$ mice also exhibit growth of axon bundles into inappropriate cranial regions and excessive and premature branching of the divisions of the trigeminal nerve, suggestive of a deficit in repulsive guidance. This effect is not likely to be mediated by a loss of Trk receptors, because most studies of the effects of neurotrophins on axon growth suggest that the neurotrophins promote axon elongation, turning, and branching rather than repulsive guidance (McFarlane and Holt, 1997; Lentz et al., 1999). The best characterized mediator of sensory axon repulsion is Sema3A, which is expressed in mesodermal and CNS tissues known to repel sensory axons (Messersmith et al., 1995; Puschel et al., 1995) and acts through its receptor Npn-1 (He and Tessier-Lavigne, 1997; Kolodkin et al., 1997). Like Brn3a ${ }^{-1-}$ embryos, mice deficient in Sema3A develop the major divisions of the trigeminal nerve but show defasciculation and projection of trigeminal axons into abnormal areas (Taniguchi et al., 1997). However, despite these defects, encirclement of the whisker follicles by trigeminal axons appears relatively normal in these mice (Ulupinar et al., 1999).

Npn-1 is strongly expressed in the trigeminal and dorsal root ganglia (Kolodkin et al., 1997, and this paper). Mice lacking Npn-1 die in utero at approximately E12.5, but before this, the developing trigeminal ganglia also extend aberrant axons similar to those observed in Brn3a ${ }^{-1-}$ mice (Kitsukawa et al., 1997). However, our results show that Brn $3 \mathrm{a}^{-/-}$mice express Npn-1 in the trigeminal and dorsal root ganglia and in their central and peripheral nerve roots. Still, defects in the Sema3A/Npn-1 signaling pathway remain a feasible explanation for the abnormal axon pathfinding in mice lacking Brn3a. One possible mechanism is a defect in the expression of Npn-1 cofactors that may be necessary to form a functional receptor complex, such as members of the plexin family, at least one of which is highly expressed in sensory ganglia (Takahashi et al., 1999; Tamagone et al., 1999).

\section{REFERENCES}

Arber S, Ladle DR, Lin JH, Frank E, Jessell TM (2000) ETS gene Er81 controls the formation of functional connections between group $1 \mathrm{a}$ sensory afferents and motor neurons. Cell 101:485-496.

Carr VM, Simpson SB (1978) Proliferative and degenerative events in the early development of chick dorsal root ganglia. II. Responses to altered peripheral fields. J Comp Neurol 182:741-756.

Cui S, Goldstein RS (2000) Early markers of neuronal differentiation in DRG: Islet-1 expression precedes that of Hu. Dev Brain Res 121:209-221.

Davies A, Lumsden A (1984) Relation of target encounter and neuronal death to the nerve growth factor responsiveness in the developing mouse trigeminal ganglion. J Comp Neurol 223:124-137.

Ericson J, Thor S, Edlund T, Jessell TM, Yamada T (1992) Early stages of motor neuron differentiation revealed by expression of homeobox gene Islet-1. Science 256:1555-1560.

Erkman L, McEvilly RJ, Luo L, Ryan AK, Hooshmand F, O'Connell SM, Keithley EM, Rapaport DH, Ryan AF, Rosenfeld MG (1996) Role of transcription factors Brn-3.1 and Brn-3.2 in auditory and visual system development. Nature 381:603-606.

Fedtsova N, Turner EE (1995) Brn3.0 expression identifies early postmitotic CNS neurons and sensory neural precursors. Mech Dev 53:291-304

Fedtsova N, Turner EE (1997) Inhibitory effects of ventral signals on the development of Brn-3.0-expressing neurons in the dorsal spinal cord. Dev Biol 190:18-31.

Fode C, Gradwohl G, Morin X, Dierich A, LeMeur M, Goridis C, Guillemot F (1998) The bHLH protein NEUROGENIN 2 is a determination factor for epibranchial placode-derived sensory neurons. Neuron 20:483-494.

Fundin BT, Silos-Santiago I, Ernfors P, Fagan AM, Aldskogius H, DeChiara TM, Phillips HS, Barbacid M, Yancopoulos GD, Rice FL (1997) Differential dependency of cutaneous mechanoreceptors on neurotrophins trk receptors and P75 LNGR. Dev Bio1 190:94-116.

Gan L, Xiang M, Zhou L, Wagner DS, Klein WH, Nathans J (1996) POU-domain factor Brn-3b is required for the development of a large set of retinal ganglion cells. Proc Natl Acad Sci USA 93:3920-3925.

Geffen R, Goldstein RS (1996) Rescue of sensory ganglia that are programmed to degenerate in normal development: evidence that NGF modulates proliferation of DRG cells in vivo. Dev Biol 178:51-62.

Gerrero MR, McEvilly R, Turner E, Lin C, O'Connell S, Jenne K, Hobbs MV, Rosenfeld MG (1993) The mammalian POU Protein Brn-3 is linked to the pituitary B cells and sensory neuronal development. Proc Natl Acad Sci USA 90:10841-10845.

Gruber CA, Rhee JM, Gleiberman A, Turner EE (1997) POU-domain factors of the Brn-3 class recognize functional DNA elements which are distinctive, symmetrical, and highly conserved in evolution. Mol Cell Biol 17:2391-2400.

He Z, Tessier-Lavigne M (1997) Neuropilin is a receptor for the axonal chemorepellent Semaphorin III. Cell 90:739-751.

Huang EJ, Zang K, Schmidt A, Saulys A, Xiang M, Reichardt LF (1999) POU domain factor Brn-3a controls the differentiation and survival of trigeminal neurons by regulating Trk receptor expression. Development 126:2869-2882.

Johnson EM, Gorin PD, Brandeis LD, Pearson J (1980) Dorsal root ganglion neurons are destroyed by exposure in utero to maternal antibody to nerve growth factor. Science 210:916-918.

Kant R, Goldstein RS (1999) Plasticity of axial identity among somites: cranial somites can generate vertebrae without expressing hox genes appropriate to the trunk. Dev Biol 216:507-520.

Kessel M, Gruss P (1991) Homeotic transformations of murine vertebrae and concomitant alteration of hox codes induced by retinoic acid. Cell 67:89-104.

Kitsukawa T, Shimizu M, Sanbo M, Hirata T, Taniguchi M, Bekku Y, Yagi T, Fujisawa H (1997) Neuropilin-Semaphorin III/D mediated chemorepulsive signals play a crucial role in peripheral nerve projection in mice. Neuron 19:995-1005.

Klein R, Silos-Santiago I, Smeyne RJ, Lira SA, Brambilla R, Bryant S, Zhang L, Snider WD, Barbacid M (1994) Disruption of the neurotrophin-3 receptor gene trkC eliminates Ia muscle afferents and results in abnormal movements. Nature 368:249-251.

Kolodkin AL, Levengood D, Rowe EG, Tai Y, Giger RJ, Ginty DD (1997) Neuropilin is a semaphorin III receptor. Cell 90:753-762.

Lentz SI, Knudson MC, Korsmeyer SJ, Snider WD (1999) Neurotrophins support the development of diverse sensory axon morphologies. J Neurosci 19:1038-1048.

Lim TM, Lunn ER, Keynes RJ, Stern CD (1987) The differing effect of occipital and trunk somites on neural development in the chick embryo. Development 100:525-533.

Logan C, Khoo WK, Cado D, Joyner AL (1993) Two enhancer regions in the mouse En-2 locus direct expression to the mid/hindbrain region and mandibular myoblasts. Development 117:905-916.

Ma Q, Chen Z, Barrantes I, de la Pompa JL, Anderson DL (1998) Neurogenin 1 is essential for the determination of neuronal precursors for proximal sensory ganglia. Neuron 20:469-482.

McEvilly RJ, Erkman L, Luo L, Sawchenko PE, Ryan AF, Rosenfeld MG (1996) Requirement for Brn-3.0 in differentiation and survival of sensory and motor neurons. Nature 384:574-577.

McFarlane S, Holt CE (1997) Growth factors: a role in guiding axons? Trends Cell Biol 7:424-430.

Messersmith EK, Leonardo ED, Shatz CJ, Tessier-Lavigne M, Goodman CS, Kolodkin AL (1995) Semaphorin III can function as a selective chemorepellant to pattern sensory projections in the spinal cord. Neuron 14:949-959.

O'Connor R, Tessier-Lavigne M (1999) Identification of maxillary factor, a maxillary process-derived chemoattractant for developing trigeminal sensory axons. Neuron 24:165-178.

Patel TD, Jackman A, Rice FL, Kucera J, Snider WD (2000) Development of sensory neurons in the absence of NGF/TrkA signalling in vivo. Neuron 25:345-357.

Paves H, Saarma M (1997) Neurotrophins as in vitro growth cone guidance molecules for embryonic sensory neurons. Cell Tissue Res 290:285-297. 
Perez S, Rebelo S, Anderson DJ (1999) Early specification of sensory neuron fate revealed by expression and function of neurogenins in the chick embryo. Development 126:1715-1728.

Pfaff SL, Mendelsohn M, Stewart CL, Edlund T, Jessell TM (1996) Requirement for LIM homeobox gene Isl-1 in motor neuron generation reveals a motor neuron-dependent step in interneuron differentiation. Cell 84:309-320.

Pinon LG, Minichiello L, Klein R, Davies AM (1996) Timing of neuronal death in trkA, trkB and trkC mutant embryos reveals developmental changes in sensory neuron dependence on Trk signalling. Development 122:3255-3261.

Puschel AW, Adams RH, Betz H (1995) Murine semaphorinD/collapsin is a member of a diverse gene family and creates domains inhibitory for axonal extension. Neuron 14:941-948.

Rokx JTM, Juch PJW, vanWillingen JD (1986) Arrangement and connections of mesencephalic trigeminal neurons in the rat. Acta Anat 127:7-15.

Rosen O, Geffen R, Avivi C, Goldstein RS (1996) Growth, proliferation, and cell death in the ontogeny of transient DRG (Froriep's ganglia) of chick embryos. J Neurobiol 30:219-230.

Rubenstein JLR, Puelles L (1994) Homeobox gene expression during development of the vertebrate brain. Curr Top Dev Biol 29:1-63.

Snider WD (1994) Functions of the neurotrophins during nervous system development: What the knockouts are teaching us. Cell 77:627638.

Takahashi T, Fournier A, Nakamura F, Wang L, Murakami Y, Kalb RG, Fujisawa H, Strittmatter SM (1999) Plexin-neuropilin-1 complexes form functional semaphorin-3A receptors. Cell 99:59-69.

Tamagone L, Aritgiani S, Chen H, He Z, Ming G, Song H, Chedotal A, Winberg ML, Goodman CS, Poo M, Tessier-Lavigne M, Comoglio PM
(1999) Plexins are a large family of receptors for transmembrane, secreted, and GPI-anchored semaphorins in vertebrates. Cell 99:71-80.

Taniguchi M, Yuasa S, Fujisawa H, Naruse I, Saga S, Mishina M, Yagi T (1997) Disruption of semaphorin III/D gene causes severe abnormality of peripheral nerve projection. Neuron 19:519-530.

Theiler K (1989) The house mouse: atlas of embryonic development. New York: Springer.

Tremblay P, Kessel M, Gruss P (1995) A transgenic neuroanatomical marker identifies cranial neural crest deficiencies associated with the Pax3 mutant Splotch. Dev Biol 171:317-329.

Trieu M, Rhee JM, Fedtsova N, Turner EE (1999) Autoregulatory sequences are revealed by complex stability screening of the mouse brn-3.0 locus. J Neurosci 19:6549-6558.

Turner EE, Fedtsova N, Rosenfeld MG (1996) POU-domain factor expression in the trigeminal ganglion and implications for herpes virus regulation. NeuroReport 7:2829-2832.

Ulupinar E, Datwani ABehar O, Fujisawa H, Erzurmulu R (1999) Role of semaphorin III in the developing rodent trigeminal system. Mol Cell Neurosci 13:281-292.

Xiang M, Lin G, Zhou L, Klein WH, Nathans J (1996) Targeted deletion of the mouse POU-domain gene Brn-3a causes a selective loss of neurons in the brainstem and trigeminal ganglion, uncoordinated limb movement, and impaired suckling. Proc Natl Acad Sci USA 93:11950-11955

Xiang M, Gan L, Zhou L, Klein WH, Nathans J (1997a) Essential role of POU-domain factor Brn-3c in auditory and vestibular hair cell development. Proc Natl Acad Sci USA 93:1950-1955.

Xiang M, Gan L, Li D, Zhou L, Chen Y, Wagner D, O'Malley BW, Klein W, Nathans J (1997b) Role of the Brn-3 family of POU-domain genes in the development of the auditory/vestibular, somatosensory, and visual systems. Cold Spring Harb Symp Quant Biol 52:325-336. 